\title{
PROMOTING AND DEMANDING
}

Dear Reader,

As part of its National Development Programme for Electric Mobility, the German government intends to provide considerable funding for research and development activities in this field over the next few years. The sum of up to two billion euros is under discussion. Of course, promoting the development of electric vehicles makes sense, whether it is to enable vehicles to have zero emissions locally, or even - if the energy comes from regenerative sources - to be carbon-neutral. It is also correct that there is some catching up to be done in research and development on electric traction, and this is the aim of this latest government funding.

Nevertheless, one should not ignore the fact that the market share of fully electric vehicles is expected to remain negligibly small in the foreseeable future. In all likelihood, they will account for a maximum of just 5 percent of newly registered vehicles in 2020. Or to put it another way: 95 percent of vehicles sold will still be powered by a diesel or gasoline engine. Engine manufacturers and their suppliers are making great efforts to further reduce $\mathrm{CO}_{2}$ emissions, in some cases through their own research and in others through joint projects, for example under the umbrella of the Research Association of Combustion Engines (FVV). But as far as internal combustion engines are concerned, the government seems to rely solely on legislation that makes demands, as well as on market forces. In contrast to electric mobility, no research funds have been allocated in this area.
As has been demonstrated, the internal combustion engine still has considerable potential for improvement. According to a projection by Bosch, engine optimisation alone can reduce $\mathrm{CO}_{2}$ emissions by up to 30 percent, and when combined with modifications to the vehicle itself the figure will be 40 percent, with hybridisation offering a further 10 percent reduction. These potential savings should be implemented as quickly as possible in fully developed products, also for the benefit of our environment. The government's funding policy, however, ignores one of the best levers for achieving a fast and comprehensive reduction in $\mathrm{CO}_{2}$ emissions. What is your opinion on the subject? You can have your say by sending an email to Richard.Backhaus@rbcommunications.de or by contributing to the blog at www.ATZonline.de. I look forward to hearing from you.

Best regards,

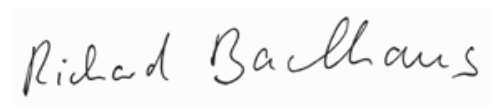

RICHARD BACKHAUS,

Vice-Editor in Chief MTZ

Wiesbaden, 15 March 2012

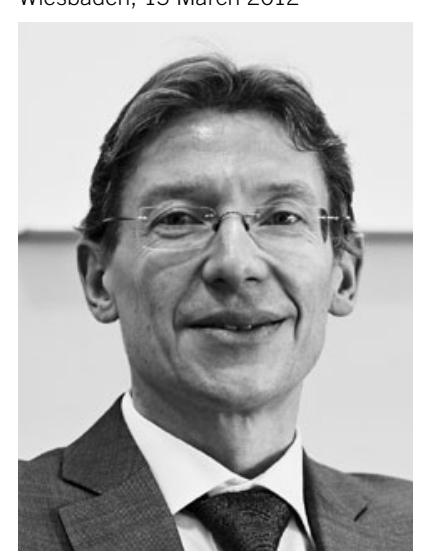

